\title{
QUALIDADE DE GRÃOS DE MILHO SUBMETIDOS AO PROCESSO DE SECA-AERAÇÃO ${ }^{1}$
}

\author{
Ivano Alessandro Devilla², Sandra Maria Couto ${ }^{3}$, Daniel Marçal de Queiroz ${ }^{4}$, \\ Guido de Souza Damasceno ${ }^{5} \&$ Fernando Pinheiro Reis $^{6}$
}

\begin{abstract}
RESUMO
Com o presente trabalho, objetivou-se a avaliação do processo de seca-aeração na qualidade final de grãos de milho (Zea mays L.) da variedade Pioneer 3041. Amostras de milho foram submetidas ao processo de seca-aeração, com três temperaturas de secagem $\left(45,55\right.$ e $\left.65^{\circ} \mathrm{C}\right)$ e cinco períodos de repouso $(0,4,8,12 \mathrm{e} 16 \mathrm{~h})$. Ao final do processo, o teor de umidade do produto e a sua qualidade foram avaliados, usando-se os parâmetros susceptibilidade a quebra, danos internos e externos, grãos ardidos e presença de micotoxinas. Conclui-se que, quanto maior a temperatura de secagem e o tempo de repouso, maior também será a redução no teor de umidade final. O processo de seca-aeração reduziu a susceptibilidade à quebra do produto e à percentagem de grãos, com danos internos; entretanto, não influenciou na percentagem de grãos ardidos nem propiciou a produção de micotoxinas.
\end{abstract}

Palavras-chave: Zea mays L., qualidade, seca-aeração

\section{QUALITY OF CORN GRAINS SUBMITTED TO DRYERATION PROCESS}

\begin{abstract}
The objective of this research was to evaluate the effect of the dryeration process on the final quality of corn (Zea mays L.) of the variety Pioneer 3041. Corn samples were submitted to the dryeration process, at three drying temperatures $\left(45,55\right.$ and $\left.65^{\circ} \mathrm{C}\right)$ and five tempering periods $(0,4,8,12$ and $16 \mathrm{~h})$. The product moisture content, as well its quality using the following parameters was evaluated: susceptibility to breakage, internal damage, external damage, burned grains and presence of micotoxines. The results indicated that the higher the drying temperature and resting period, the higher the reduction in the final moisture content. The dryeration process reduced the susceptibility to breakage and the percentage of grains with internal damages, but did not influence the percentage of burnt grains and production of micotoxines.
\end{abstract}

Key words: Zea mays L., quality, dryeration

\section{INTRODUÇÃO}

O sistema de produção agrícola brasileiro apresenta elevados índices de perda, causada por danos físicos durante as operações de colheita, transporte, secagem e armazenagem, ou por agentes biológicos como insetos, roedores, microrganismos e pela própria respiração dos grãos. Atualmente, a qualidade dos grãos agrícolas tem-se tornado aspecto muito importante, tanto para \footnotetext{
Av. PH. Rolfs s/n, CEP 36571 - 000, Viçosa, MG

${ }^{2}$ Aluno de Doutorado; Msc; DEA; UFV. Fone: (031) 891 9739, E-mail: devilla@alunos.ufv.br

${ }^{3}$ Professora Adjunto; Ph.D.; DEA; UFV. Fone: (031) 899 1925, E-mail: scouto@ mail.ufv.br

${ }^{4}$ Professor Adjunto; Ph.D.; DEA; UFV. Fone: (031) 899 1882, E-mail: queiroz@ mail.ufv.br

${ }^{5}$ Professor Titular; Ph.D.; DEA; UFV. Fone: (031) 899 1927, E-mail: gdamasc@ mail.ufv.br

${ }^{6}$ Professor Adjunto; Msc.; DPI; UFV. Fone: (031) 8991782
}

${ }^{1}$ Parte da Dissertação de Mestrado do primeiro autor , Departamento de Engenharia Agrícola (DEA); Universidade Federal de Viçosa (UFV); 
comercialização interna como para exportação. Dos processos pós-colheita, a secagem do produto é um determinante para a manutenção da qualidade dos grãos, além de ser a fase em que o consumo de energia é mais significativo. Comparada com os métodos convencionais, a seca-aeração reduz de 15 a $30 \%$ o consumo de energia, aumentando acima de $50 \%$ a capacidade do secador e proporcionando grãos menos susceptíveis à quebra (Sauer, 1992). No processo de seca-aeração, os grãos, após a secagem, são acumulados em um silo, por um período de 4 a $12 \mathrm{~h}$ (redistribuição da umidade) sendo, então, resfriados com fluxos de ar de 0,5 a 0,6 m min $^{-1} \mathrm{t}^{-1}$ de grãos (Mckenzie et al., 1967; Lasseran, 1978; Cunha, 1980).

Thompson \& Foster (1967) estudando o processo de seca-aeração de milho, concluíram que: a) o processo reduziu em $80 \%$ a susceptibilidade à quebra, atribuída a tensões térmicas; b) a maior percentagem de grãos sem trincas, $63 \%$, ocorreu para um tempo de repouso de $12 \mathrm{~h}$; c) para um fluxo de ar de $0,5 \mathrm{~m}^{3} \mathrm{~min}^{-1} \mathrm{t}^{-1}$, temperatura de secagem de $115,6{ }^{\circ} \mathrm{C}$ e tempo de repouso de $8 \mathrm{~h}$, houve a maior quantidade de umidade removida ( 2 pontos percentuais).

Este trabalho teve por objetivo a avaliação dos efeitos do processo de seca-aeração, utilizando-se várias temperaturas de secagem e tempos de repouso na redução do teor de umidade e na qualidade de grãos de milho (Zea mays L.) da variedade Pioneer 3041.

\section{MATERIAL E MÉTODOS}

Grãos de milho variedade Pioneer 3041, safra 1996/1997, procedentes do município de Costa Rica, MS, tiveram, depois da homogeneização, sua umidade determinada de acordo com as Regras para Análise de Sementes (Brasil, 1992). Em camada fina, a secagem das amostras foi realizada em um secador de laboratório com controle de temperatura e vazão do ar, mantida em $60 \mathrm{~m}^{3} \mathrm{~min}^{-1} \mathrm{~m}^{-2}$. As temperaturas de secagem atingidas pelos grãos foram de 45,55 e $65^{\circ} \mathrm{C}$; as amostras foram secas até a umidade final de, aproximadamente, $16 \%$ b.u. realizando-se, também, a secagem das amostras de milho em condições ambientais.

Depois da secagem, as amostras, acondicionadas em recipientes de isopor, permaneceram por períodos de repouso de $0,4,8,12$ e $16 \mathrm{~h}$; a seguir, foram retiradas dos recipientes e expostas ao ar ambiente por $2 \mathrm{~h}$ finalizando, assim, seu resfriamento, enquanto aquelas submetidas a um tempo de repouso de $0 \mathrm{~h}$ foram expostas ao ar ambiente imediatamente depois da secagem; ao final do resfriamento, as umidades finais das amostras foram determinadas e estas, acondicionadas em sacos de polietileno, foram armazenadas em refrigerador $\left(5^{\circ} \mathrm{C}\right)$ onde permaneceram até os testes para avaliação de qualidade.

Os testes de susceptibilidade à quebra das amostras foram realizados em um "Stein Breakage Tester", modelo CK. Uma amostra de $100 \mathrm{~g}$ de grãos, acomodada em um recipiente de aço (9 $\mathrm{cm}$ de diâmetro) foi submetida, por $4 \mathrm{~min}$, a impactos provenientes da hélice do aparelho (1800 rpm) que propelia os grãos contra a parede do recipiente; a seguir, a amostra foi peneirada em um crivo de furos de $4,76 \mathrm{~mm}$ de diâmetro e o percentual do produto (em peso) não retido na peneira foi considerado índice de susceptibilidade à quebra. Esta avaliação foi realizada depois do resfriamento total do produto, sempre com grãos a $23^{\circ} \mathrm{C}$.
Amostras aleatórias de 50 grãos (em três repetições) de cada unidade experimental, foram inspecionadas visualmente, para a avaliação das percentagens de grãos com danos internos, externos e ardidos; de início, avaliaram-se os danos externos e os grãos classificados como "sem danos externos" foram, então, avaliados e separados em duas categorias: "ardido" e "não ardido"; apenas os grãos da amostra classificados como "sem danos externos" e "não ardidos", foram examinados para avaliação de danos internos.

Para a análise de micotoxinas usou-se uma amostra de $100 \mathrm{~g}$ de grão, composta de aproximadamente $35 \mathrm{~g}$ de grão de cada uma das três amostras de cada unidade experimental; essas amostras foram enviadas ao Laboratório de Análises Micotoxicológicas da Universidade Federal de Santa Maria, RS, onde foram avaliadas as seguintes micotoxinas: Aflatoxina $B_{1}$, Aflatoxina $B_{2}$, Aflatoxina $G_{1}$, Aflatoxina $G_{2}$, Zearalenona e Ocratoxina A, segundo metodologia utilizada por Soares \& Rodriguez-Amaya (1989).

\section{RESULTADOS E DISCUSSÃO}

\section{Teor de umidade}

O processo de secagem das amostras de milho propiciou, em diferentes temperaturas, redução média no teor de umidade dos grãos de $23,3 \pm 0,4 \%$ para $16,5 \pm 0,5 \%$ b.u.

Ao final do processo de seca-aeração, no qual as amostras permaneceram em repouso por diferentes intervalos de tempo, estas se encontravam com teor médio de umidade de 15,5 \pm 0,5\% b.u.; houve, assim, redução média de 1 ponto percentual base úmida de umidade durante o repouso e resfriamento.

A Tabela 1 apresenta, nas diferentes combinações de temperatura de secagem e tempo de repouso os valores médios, com os respectivos desvios-padrão, dos teores de umidade antes da secagem, no início do período de repouso (inicial) e depois a este período (final) e, também, os tempos de secagem, valores médios das temperaturas e umidade relativa do ambiente durante o resfriamento e as umidades de equilíbrio do grão para estas condições.

Ao se comparar os valores médios dos teores de umidade das amostras logo depois da secagem com aqueles relativos às amostras submetidas a zero hora de repouso (permanência de $2 \mathrm{~h}$ em condições ambientais para resfriamento), de acordo com a Tabela 1, observa-se tendência de amostras com maiores teores de umidade finais ao se diminuir a temperatura de secagem. As condições ambientais médias foram de $26,8 \pm 1{ }^{\circ} \mathrm{Ce} 66,1 \pm 3 \%$ de umidade relativa.

A Figura 1 apresenta a equação de regressão ajustada para a variação do teor de umidade final das amostras, em função do tempo de repouso $(0-16 \mathrm{~h})$ e da temperatura de secagem e, também, cortes desta superfície de resposta para as temperaturas de 45,55 e $65^{\circ} \mathrm{C}$.

Verifica-se que, para as três temperaturas de secagem, o teor de umidade final das amostras diminui com aumentos no tempo de repouso e na temperatura de secagem.

A redução máxima no teor de umidade, 1,6 ponto percentual em base úmida, ocorreu para temperatura de $65^{\circ} \mathrm{C}$ e tempo de repouso de $8 \mathrm{~h}$, resultado este inferior à redução de umidade máxima, $2 \%$, determinada por Thompson \& Foster (1967) em um processo de seca-aeração de grãos de milho, usando temperatura 
Tabela 1. Teores de umidade das amostras de milho nos diferentes estágios do processo de seca-aeração, em diferentes temperaturas de secagem (TS) e tempos de repouso (TR) com os respectivos tempos de exposição, condições ambientais e de equilíbrio do grão durante o resfriamento

\begin{tabular}{|c|c|c|c|c|c|c|c|c|}
\hline \multirow{2}{*}{$\begin{array}{l}\mathrm{TS} \\
\left({ }^{\circ} \mathrm{C}\right)\end{array}$} & \multirow{2}{*}{$\begin{array}{l}\text { TR } \\
\text { (h) }\end{array}$} & \multicolumn{3}{|c|}{ Umidade (\% b.u.) } & \multirow{2}{*}{$\begin{array}{l}\text { Tempo de } \\
\text { Secagem } \\
\text { (h) }\end{array}$} & \multicolumn{3}{|c|}{$\begin{array}{c}\text { Condições Ambientais } \\
\text { Resfriamento }\end{array}$} \\
\hline & & IAS $^{*}$ & $\begin{array}{l}\text { Repouso } \\
\text { Inicial }\end{array}$ & $\begin{array}{l}\text { Resfriamento } \\
\quad \text { Final }\end{array}$ & & $\begin{array}{c}\text { Temperatura } \\
\left({ }^{\circ} \mathrm{C}\right)\end{array}$ & $\begin{array}{l}\text { UR } \\
(\%)\end{array}$ & $\begin{array}{l}\mathrm{UE}^{* *} \\
(\%\end{array}$ \\
\hline \multirow[t]{5}{*}{45} & 0 & $23,3 \pm 0,5$ & $16,5 \pm 0,3$ & $16,3 \pm 0,8$ & 1,7 & $28,0 \pm 1$ & $66,0 \pm 1$ & 13,2 \\
\hline & 4 & $23,1 \pm 0,3$ & $16,7 \pm 0,6$ & $16,2 \pm 0,5$ & 1,7 & $28,0 \pm 1$ & $62,0 \pm 1$ & 12,5 \\
\hline & 8 & $23,2 \pm 0,1$ & $16,8 \pm 0,5$ & $16,0 \pm 0,5$ & 1,6 & $28,0 \pm 1$ & $62,0 \pm 3$ & 12,6 \\
\hline & 12 & $23,0 \pm 0,2$ & $16,8 \pm 0,6$ & $15,8 \pm 0,3$ & 1,6 & $27,0 \pm 1$ & $65,0 \pm 0$ & 13,2 \\
\hline & 16 & $23,6 \pm 0,3$ & $16,4 \pm 0,4$ & $15,5 \pm 0,2$ & 1,9 & $26,2 \pm 0$ & $65,0 \pm 0$ & 13,2 \\
\hline \multirow[t]{5}{*}{55} & 0 & $23,4 \pm 0,1$ & $16,4 \pm 0,7$ & $15,7 \pm 0,3$ & 1,3 & $27,0 \pm 1$ & $66,0 \pm 1$ & 13,3 \\
\hline & 4 & $23,5 \pm 0,2$ & $16,4 \pm 0,1$ & $15,5 \pm 0,3$ & 1,3 & $26,8 \pm 0$ & $66,0 \pm 1$ & 13,4 \\
\hline & 8 & $23,4 \pm 0,3$ & $16,3 \pm 0,2$ & $15,3 \pm 0,1$ & 1,3 & $26,8 \pm 0$ & $67,0 \pm 1$ & 13,6 \\
\hline & 12 & $23,3 \pm 0,2$ & $16,3 \pm 0,5$ & $15,3 \pm 0,0$ & 1,4 & $26,0 \pm 1$ & $68,0 \pm 0$ & 13,8 \\
\hline & 16 & $23,4 \pm 0,3$ & $16,4 \pm 0,3$ & $15,2 \pm 0,1$ & 1,2 & $26,0 \pm 0$ & $66,0 \pm 2$ & 13,4 \\
\hline \multirow[t]{5}{*}{65} & 0 & $23,3 \pm 0,2$ & $16,1 \pm 0,5$ & $15,3 \pm 0,6$ & 1,0 & $28,0 \pm 2$ & $71,0 \pm 3$ & 14,2 \\
\hline & 4 & $23,2 \pm 0,1$ & $16,7 \pm 0,8$ & $15,2 \pm 0,1$ & 0,9 & $27,0 \pm 2$ & $69,0 \pm 3$ & 13,9 \\
\hline & 8 & $23,3 \pm 0,0$ & $16,8 \pm 0,2$ & $15,2 \pm 0,4$ & 0,8 & $26,8 \pm 0$ & $67,0 \pm 0$ & 13,5 \\
\hline & 12 & $23,2 \pm 0,1$ & $16,1 \pm 0,3$ & $15,1 \pm 0,4$ & 0,9 & $27,0 \pm 0$ & $65,0 \pm 3$ & 13,1 \\
\hline & 16 & $23,3 \pm 0,1$ & $16,1 \pm 0,6$ & $14,8 \pm 0,7$ & 0,9 & $26,0 \pm 1$ & $66,0 \pm 1$ & 13,4 \\
\hline $\mathrm{Ar}$ & Natural & $23,3 \pm 0,2$ & & $15,6 \pm 0,2$ & 48,0 & $26,2 \pm 0$ & $65,0 \pm 1$ & 13,2 \\
\hline
\end{tabular}

* IAS - Imediatamente antes da secagem; ** UE - Umidade de equilíbrio dos grãos

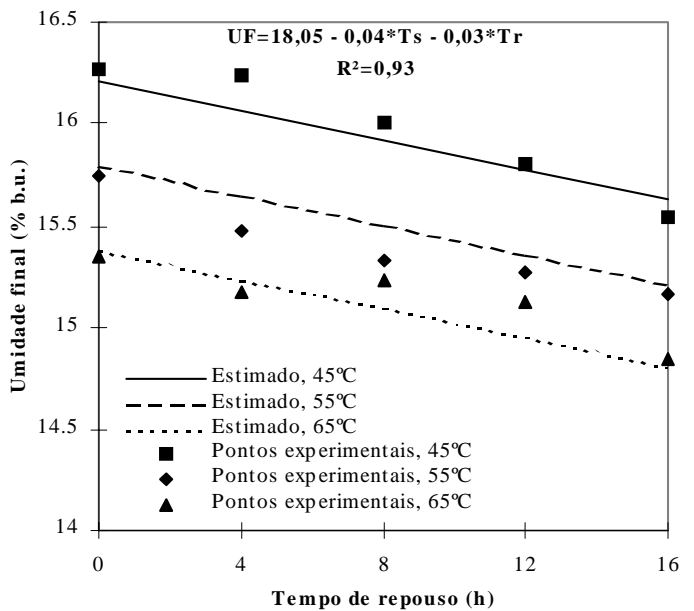

Figura 1. Variação do teor de umidade final das amostras de milho em função da temperatura de secagem e do tempo de repouso ( ${ }^{*}$ Significativo a $5 \%$ de probabilidade pelo teste $\mathrm{t}$ )

de secagem de $115,6^{\circ} \mathrm{C}$, tempo de repouso de $8 \mathrm{~h}$ e resfriamento com fluxo de ar de $0,56 \mathrm{~m}^{3} \mathrm{~min}^{-1} \mathrm{t}$. Como a redução de umidade depende da temperatura de secagem, quanto maior a temperatura, maior também a redução de umidade.

\section{Susceptibilidade a quebra}

Valores médios da susceptibilidade a quebra, encontrados nas amostras de milho submetidas ao processo de seca-aeração, variaram de 2,6 a 5,0 \% (Tabela 2). Esses valores são inferiores aos obtidos por Thompson \& Foster (1967) 6,7\%, depois da secagem de milho de $25 \%$ b.u. para $14 \%$ b.u., nas temperaturas de 87,$8 ; 115,6$ e $143,3^{\circ} \mathrm{C}$, indicando que as amostras processadas neste trabalho apresentaram, ao final, menores níveis de dano.

A Tabela 2 apresenta os valores médios com os respectivos desvios-padrão, da susceptibilidade à quebra das amostras de milho submetidas a diferentes temperaturas de secagem e tempos de repouso.

Amostras secas ao ar natural, até $(15,6 \pm 0,2) \%$ b.u., apresentaram susceptibilidade à quebra média de $(1,7 \pm 0,5) \%$ menor que aquela obtida para amostras submetidas ao processo de seca-aeração. $\mathrm{O}$ fato de as amostras secas com ar ambiente praticamente não sofrerem estresse térmico explica, provavelmente, este resultado. Os grãos submetidos a $16 \mathrm{~h}$ de repouso apresentaram a menor susceptibilidade a quebra, nas três temperaturas de secagem, provavelmente pelo fato de apresentarem as menores percentagens de grãos sem danos.

A Figura 2 mostra a equação de regressão, ajustada para descrever a susceptibilidade à quebra das amostras de milho, em função das temperaturas de secagem e dos tempos de repouso. Cortes desta superfície, em cada temperatura de secagem são, também, apresentados na Figura 2. Observa-se que grãos com menor susceptibilidade a quebra, são obtidos diminuindo-se a temperatura de secagem e aumentando o tempo de repouso. Para os intervalos de temperatura de secagem e de tempo de repouso estudados, a melhor combinação foi a de $45^{\circ} \mathrm{Ce} 16 \mathrm{~h}$ 
Tabela 2. Susceptibilidade à quebra das amostras de milho em diferentes temperaturas de secagem e tempos de repouso

\begin{tabular}{ccc}
\hline $\begin{array}{c}\text { Temperatura } \\
\left({ }^{\circ} \mathrm{C}\right)\end{array}$ & $\begin{array}{c}\text { Tempo de repouso } \\
(\mathrm{h})\end{array}$ & $\begin{array}{c}\text { Susceptibilidade à quebra } \\
(\%)\end{array}$ \\
\hline 45 & 0 & $4,1 \pm 0,4$ \\
& 4 & $3,7 \pm 0,8$ \\
& 8 & $4,0 \pm 1,0$ \\
& 12 & $3,0+0,7$ \\
55 & 16 & $2,6 \pm 0,3$ \\
& 0 & $5,0 \pm 2,0$ \\
& 4 & $4,3 \pm 0,1$ \\
& 8 & $3,9 \pm 0,7$ \\
65 & 12 & $3,6 \pm 0,6$ \\
& 16 & $2,9 \pm 0,3$ \\
& 0 & $5,0 \pm 1,0$ \\
& 4 & $4,6 \pm 0,3$ \\
Ar natural & 8 & $4,2 \pm 0,1$ \\
\hline
\end{tabular}

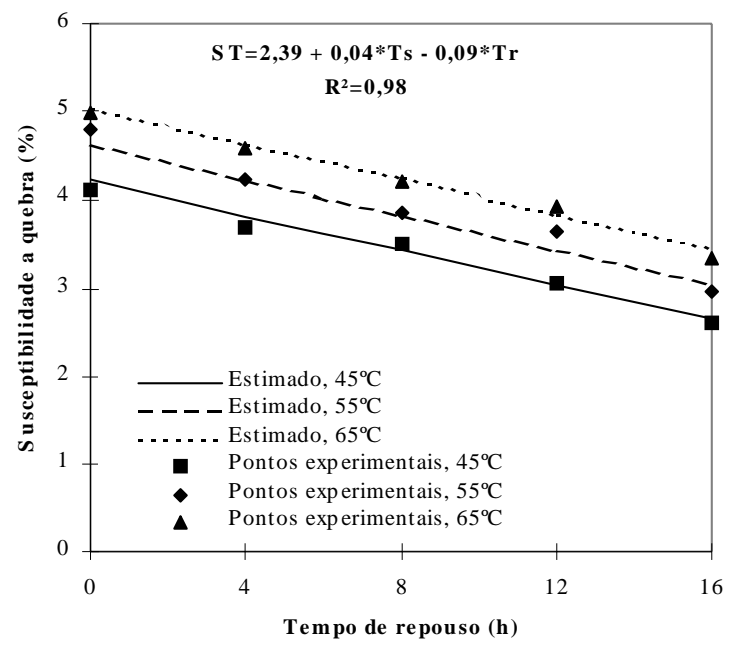

Figura 2. Variação da susceptibilidade à quebra das amostras de milho em função das temperaturas de secagem e dos tempos de repouso ( ${ }^{*}$ Significativo a $5 \%$ de probabilidade pelo teste $\mathrm{t}$ )

Considerando-se uma secagem a $45^{\circ} \mathrm{C}$, a susceptibilidade à quebra de grãos submetidos a zero h de repouso, foi 1,6 vezes maior que a daqueles que permaneceram em repouso por $16 \mathrm{~h}$; já para um tempo de repouso de $16 \mathrm{~h}$, a susceptibilidade de grãos secos a $65^{\circ} \mathrm{C}$ foi 1,3 vezes maior que a $45^{\circ} \mathrm{C}$.

\section{Danos internos, externos e grãos ardidos}

A Tabela 3 apresenta o resumo dos resultados das avaliações das amostras classificadas nas categorias sem danos, danos internos, danos externos e grãos ardidos. Observa-se que existe tendência da percentagem de grãos sem danos aumentar quando há redução da temperatura de secagem e aumento do tempo de repouso, facilmente visualizado na Figura 3, em que os percentuais de grãos sem danos, com danos (internos e externos) ardidos, são apresentados para cada temperatura de secagem e
Tabela 3. Classificação geral dos dados apresentados nas amostras de milho, em diferentes temperaturas e tempos de repouso

\begin{tabular}{|c|c|c|c|c|c|}
\hline \multirow[b]{2}{*}{ Ts } & \multirow[b]{2}{*}{$\operatorname{Tr}$} & \multicolumn{4}{|c|}{ Categoria } \\
\hline & & $\begin{array}{l}\text { Sem } \\
\text { dano }\end{array}$ & $\begin{array}{c}\text { Dano } \\
\text { interno }\end{array}$ & $\begin{array}{c}\text { Dano } \\
\text { externo }\end{array}$ & Ardidos \\
\hline$\left({ }^{\circ} \mathrm{C}\right)$ & (h) & $(\%)$ & $(\%)$ & $(\%)$ & $(\%)$ \\
\hline \multirow[t]{5}{*}{45} & 0 & $27,8 \pm 20,2$ & $40,0 \pm 3,0$ & $17,6 \pm 1,0$ & $14,7 \pm 3,0$ \\
\hline & 4 & $47,6 \pm 5,6$ & $26,2 \pm 4,0$ & $15,3 \pm 0,7$ & $10,9 \pm 3,0$ \\
\hline & 8 & $55,6 \pm 4,2$ & $20,4 \pm 3,0$ & $12,0 \pm 0,8$ & $12,0 \pm 2,0$ \\
\hline & 12 & $55,8 \pm 0,8$ & $15,8 \pm 3,0$ & $13,6 \pm 0,3$ & $14,9 \pm 3,0$ \\
\hline & 16 & $56,4 \pm 4,0$ & $17,1 \pm 4,0$ & $13,1 \pm 1,0$ & $13,3 \pm 2,0$ \\
\hline \multirow[t]{5}{*}{55} & 0 & $19,8 \pm 2,7$ & $51,6 \pm 1,0$ & $23,6 \pm 5,0$ & $13,6 \pm 3,0$ \\
\hline & 4 & $46,4 \pm 8,0$ & $30,0 \pm 6,0$ & $12,0 \pm 2,0$ & $13,6 \pm 2,0$ \\
\hline & 8 & $46,2 \pm 2,7$ & $28,0 \pm 4,0$ & $9,6 \pm 1,0$ & $15,3 \pm 3,0$ \\
\hline & 12 & $51,1 \pm 3,2$ & $19,6 \pm 4,0$ & $12,0 \pm 1,0$ & $16,2 \pm 4,0$ \\
\hline & 16 & $56,2 \pm 3,7$ & $19,1 \pm 4,0$ & $10,4 \pm 0,9$ & $11,8 \pm 3,0$ \\
\hline \multirow[t]{5}{*}{65} & 0 & $5,3 \pm 1,8$ & $70,4 \pm 11,0$ & $12,7 \pm 2,0$ & $11,6 \pm 2,0$ \\
\hline & 4 & $37,6 \pm 1,9$ & $34,7 \pm 8,0$ & $12,9 \pm 1,0$ & $14,9 \pm 0,0$ \\
\hline & 8 & $38,4 \pm 2,0$ & $35,8 \pm 9,0$ & $11,1 \pm 0,7$ & $14,7 \pm 1,0$ \\
\hline & 12 & $48,2 \pm 1,0$ & $22,2 \pm 8,0$ & $13,1 \pm 1,0$ & $16,4 \pm 3,0$ \\
\hline & 16 & $55,1 \pm 8,4$ & $23,1 \pm 5,0$ & $10,2 \pm 2,0$ & $11,6 \pm 2,0$ \\
\hline \multicolumn{2}{|c|}{ Ar natural } & $49,0 \pm 5,0$ & $19,0 \pm 2,0$ & $13,0 \pm 2,0$ & $19,0 \pm 2,0$ \\
\hline
\end{tabular}
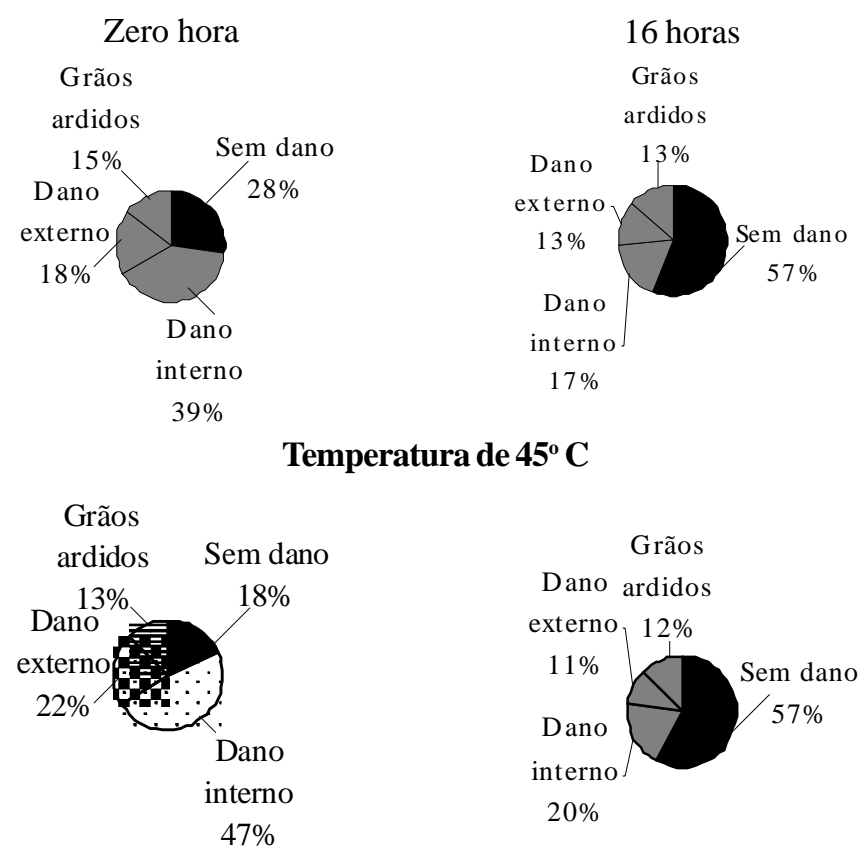

Temperatura de $45^{\circ} \mathrm{C}$

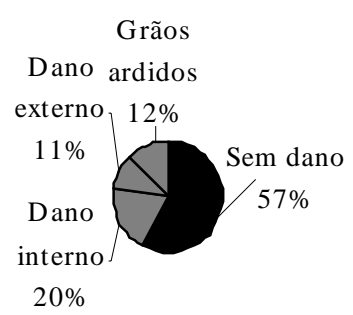

Temperatura de $55^{\circ} \mathrm{C}$

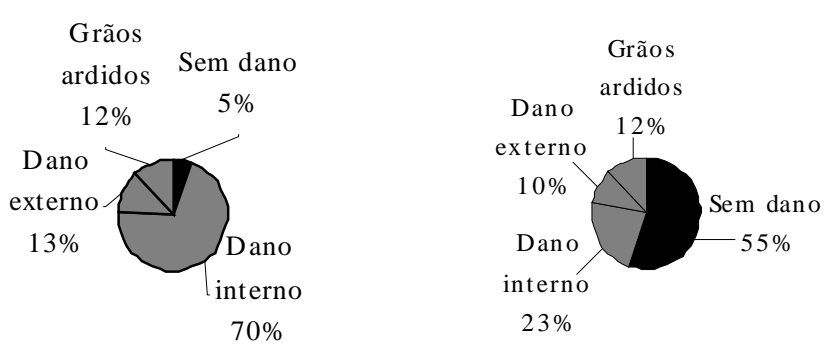

Temperatura de $65^{\circ} \mathrm{C}$

Figura 3. Percentagem de grãos classificados como sem dados, com danos (internos e externos) e ardidos, secos em três temperaturas, com tempos de repouso de zero e $16 \mathrm{~h}$ 
para os tempos de repouso extremos, zero e $16 \mathrm{~h}$. Observa-se, nesta figura que, para o tempo de repouso zero, a medida em que se aumenta a temperatura de secagem aumenta-se, também, a ocorrência de grãos com danos internos e, consequientemente, diminui o percentual dos grãos sem danos. Pode-se observar, ainda, o benefício de um resfriamento moderado dos grãos depois da secagem, ao se comparar os dois tempos de repouso extremos. No tempo de repouso $0 \mathrm{~h}$, os $28 \%$ de grãos sem danos, na temperatura de secagem de $45{ }^{\circ} \mathrm{C}$, reduzem-se a $5 \%$ na temperatura de secagem de $65^{\circ} \mathrm{C}$; no tempo de repouso de $16 \mathrm{~h}$, o processo de danificação dos grãos parece ser bem mais estável e reduzido, atenuando o efeito da temperatura de secagem.

A média dos grãos ardidos foi de $14 \pm 3 \%$ e $19 \pm 2 \%$ na secagem com processo de seca-aeração e secagem natural, respectivamente.

Para esta variável estudada não houve efeito significativo da temperatura nem do tempo de repouso.

\section{Micotoxinas}

Os resultados obtidos na análise de micotoxinas mostraram que não foi encontrado qualquer traço de Aflatoxina $B_{1}$, Aflatoxina $B_{2}$, Aflatoxina $G_{1}$, Aflatoxina $G_{2}$, Zearalenona nem de Ocratoxina $\mathrm{A}$, em nenhuma das amostras analisadas no presente estudo.

\section{CONCLUSÕES}

As análises dos dados e a interpretação dos resultados obtidos nas condições do presente trabalho, permitiram as seguintes conclusões:

1. Quanto maior a temperatura de secagem e o tempo de repouso, maior também a redução no teor de umidade das amostras.

2. Na temperatura de secagem de $65{ }^{\circ} \mathrm{C}$ e no tempo de repouso de $8 \mathrm{~h}$, a maior redução no teor de umidade foi de 1,6 ponto percentual base úmida; a menor redução, 0,2 ponto percentual base úmida, ocorreu na temperatura de secagem de $45^{\circ} \mathrm{C}$ e no tempo de repouso de $0 \mathrm{~h}$.

3. No resfriamento houve redução média de umidade de 1 ponto percentual base úmida.

4. O processo de seca-aeração reduz a susceptibilidade à quebra dos grãos.

5. A diminuição da temperatura de secagem e o aumento do tempo de repouso resultam em grãos com menor susceptibilidade a quebra.
6. Na temperatura de secagem de $45^{\circ} \mathrm{C}$, a susceptibilidade à quebra dos grãos submetidos ao tempo de repouso de $0 \mathrm{~h}$ foi 1,6 vezes maior que aquela para grãos que permaneceram em repouso por $16 \mathrm{~h}$.

7. O processo de seca-aeração reduz a percentagem de grãos com danos internos.

8. Amostras de milho secas na temperatura de $45{ }^{\circ} \mathrm{C}$ e mantidas em repouso por $16 \mathrm{~h}$ apresentaram a maior percentagem de grãos sem danos. A medida em que se diminui o tempo de repouso e se aumenta a temperatura de secagem, há maior formação de danos internos no produto.

9. O processo de seca-aeração não produziu qualquer fissura visível nos grãos.

10. O tempo de repouso e a temperatura de secagem não influenciaram na percentagem de grãos ardidos.

11. Em todos os testes realizados não foi detectada a produção de micotoxinas.

\section{REFERÊNCIAS BIBLIOGRÁFICAS}

BRASIL, Ministério da Agricultura e Reforma Agrária. Regras para análise de sementes. Brasília, 1992.365p.

CUNHA, O.P. da. Experiências com um sistema de seca-aeração. Panambi, RS.: Kepler Weber, 1980.15 p.

LASSERAN, J.C. Princípios gerais de secagem. Revista Brasileira de Armazenamento, Viçosa, v. 3, n. 3, p. 17-46, 1978.

McKENZIE, V.A.C.H.; FOSTER, R.T.; THOMPSON, R.A. Dryeration better corn-quality with high speed drying. West Lafayette, Indiana: Purdue University. 1967. 20p. Cooperative Extension Service, AE 72

SAUER, D.B. Storage of cereal grains and their products. St. Paul: American Association of Cereal Chemists, 1992. 615p. SOARES, L.M.V.; RODRIGUEZ-AMAYA, D.B. Survey of aflatoxins, ochratoxin $\mathrm{A}$, zearalenone, and sterigmatocystin in some Brazilian foods by using multi-toxin thin-layer chromatographic method. Journal Association of Analysis Chemistry, v. 72, n. 1, p. 22-26, 1989.

THOMPSON, R.A.; FOSTER, G.H. Dryeration: High speed drying with delayed aeration cooling. Detroit: ASAE, 1967. 16p. Paper, 67-843 